\title{
Correction to: Multiple criteria ranking method based on functional proximity index: un-weighted TOPSIS
}

\author{
V. Liern ${ }^{1}$ (D) B. Pérez-Gladish ${ }^{2}$ D \\ (c) Springer Science+Business Media, LLC, part of Springer Nature 2020
}

\section{Correction to: Annals of Operations Research https://doi.org/10.1007/s10479-020-03718-1}

This erratum is published due to proofing error as author corrections with equation 1 were overlooked.

Equation 1 should be read as:

$$
r_{i j}=\frac{x_{i j}}{\sqrt{\sum_{i=1}^{n}\left(x_{i j}\right)^{2}}} \in[0,1] \quad 1 \leq i \leq n, \quad 1 \leq j \leq m .
$$

Original article has been thus updated.

Publisher's Note Springer Nature remains neutral with regard to jurisdictional claims in published maps and institutional affiliations.

The original article can be found online at https://doi.org/10.1007/s10479-020-03718-1.

$\bowtie$ B. Pérez-Gladish bperez@uniovi.es

1 University of Valencia, Valencia, Spain

2 University of Oviedo, Oviedo, Spain 